\title{
HGIS AND ARCHIVE RESEARCHES: A TOOL FOR THE STUDY OF THE ANCIENT MILL CHANNEL OF CESENA (ITALY)
}

\author{
G. Bitelli a , F. Bartolini ${ }^{\mathrm{b}}$, G. Gatta ${ }^{\mathrm{a}, *}$ \\ a Dept. of Civil, Chemical, Environmental and Materials Engineering, University of Bologna, viale Risorgimento 2, 40136 Bologna - \\ gabriele.bitelli@unibo.it; giorgia.gatta@unibo.it \\ b Civil and Environmental Engineer - ing.arch.fabiobartolini@live.it
}

Commission V, WG V/2

KEY WORDS: HGIS, historical cartography, georeferencing, archive search, mill channel, Cesena, industrial archaeology

\begin{abstract}
:
The present study aims to demonstrate the usefulness of GIS to support archive searches and historical studies (e.g. related to industrial archaeology), in the case of an ancient channel for mill powering near Cesena (Emilia-Romagna, Italy), whose history is weaved together with the history of the Compagnia dei Molini di Cesena mill company, the most ancient limited company in Italy. Several historical maps (about 40 sheets in total) inherent the studied area and 80 archive documents (drawings, photos, specifications, administrative acts, newspaper articles), over a period of more than 600 years, were collected. Once digitized, historical maps were analysed, georeferenced and mosaicked where necessary. Subsequently, in all the maps the channel with its four mills and the Savio river were vectorized. All the additional archive documents were digitized, catalogued and stored. Using the QGIS open source platform, a Historical GIS was created, encompassing the current cartographic base and all historical maps, with their vectorized elements; each archive document was linked to the proper historical map, so that the document can be immediately retrieved and visualized.

In such a HGIS, the maps form the base for a spatial and temporal navigation, facilitated by a specific interface; the external documents linked to them complete the description of the represented elements. This simple and interactive tool offers a new approach to archive searches, as it allows reconstruction in space and time of the evolution of the ancient channel and the history of this important mill company.
\end{abstract}

\section{INTRODUCTION}

1.1 Digital regeneration of ancient cartography and archival sources

Historical cartography is a fundamental part of Cultural Heritage, which needs to be recovered, preserved and accessed. Today, digital regeneration of ancient cartography is an interesting way not only to save documents from extinction but also to allow new chances of viewing and using its historic and geographic information, by modalities that cannot apply to analogue supports. To the aim, Geomatics science can provide many tools and techniques, among which: georeferencing, analysis of the metric fidelity of the ancient maps, comparison with other cartographic databases, change analysis and analytical procedures in a GIS (Geographic Information System) environment, virtual metric reconstructions, etc. (Balletti, 2000; Bitelli et al., 2014; Livieratos, 2006).

Once digitized and processed, cartographic heritage appears more accessible to and usable by many kinds of users: not only experts (researchers, archivists, historians, technicians), but also citizens, tourists, map-lovers, etc.

The textual documents stored in archival databases, on the other hand, can be more easily accessed if they are digitized and georeferenced in implicit or explicit way. When put in relationship with cartographic data coming from the same period, they can assume a new level of interest or provide a new kind of information. The geographic metadata associated to textual documents can furthermore support more efficient searches in the archives.

\subsection{Historical Geographic Information Systems}

A fast and efficient way to manage Cartographic Heritage in digital form is a GIS environment, with the production of a socalled "Historical GIS" (HGIS). Geographical Information Systems appear useful in management of amounts of historical data related to specific geographical areas, or investigation of a specific topic over space and time. The fact relies on the potentialities of GIS, among which: georeferencing of data and management by means of thematic layers, quantitative analysis by means of ad-hoc tools, integration of different kinds of data (e.g. texts or images) differently aged and coming from different sources, consultation of distributed data over space and time, sharing with other users, etc.

The great utility of GIS in management of historical cartographic data is proved by many HGIS projects that have been developed in recent years for various purposes, at both national and urban scale (Gregory and Healey, 2007; Larson, 2003; Schlichting 2008; Wilson, 2001). Another proof is given by the great variety of studies that recently have been carried out (e.g.: Brovelli et al., 2016; Gatta and Bitelli, 2016; Lundberg and Peterson, 2005; Nobajas, 2014; Timár et al., 2008).

\footnotetext{
* Corresponding author
} 


\subsection{Environmental changes and industrial archaeology}

The present study is just intended to demonstrate the usefulness of HGIS to support archive searches and historical studies. In particular, the research started from the consideration that a significant topic of interest, not always well considered when studying the changes occurred in an area during the last centuries, refers to industrial archaeology or in general the evolution of infrastructures and industrial complexes in relation with the environmental context (Casella and Symonds, 2005; Cossons, 2000). This theme offers very interesting opportunities when one turns to the industries related to water and power generation (Bitelli et al, 2011).

An interesting case is given by the ancient channel for mill powering near Cesena (Emilia-Romagna, Italy), that can be considered an example of industrial archaeology. The channel had been the engine of the agricultural economy of the city for over six centuries; its history is strictly weaved together with the history of the Compagnia dei Molini di Cesena mill company, the most ancient limited company in Italy. As a matter of fact, the Municipality of Cesena is promoting the recovery of one mill (Serravalle), today no longer in operation, through collaboration with private or associations: a project today under discussion is the redevelopment of the building in a local urban archaeology museum (Bianchi, 2013).

\section{THE CASE STUDY}

\subsection{The ancient channel for mill powering near Cesena}

Cesena is a city of almost 10000 inhabitants, located in the east side of the Emilia-Romagna region (Italy), along the Via Emilia street between Forlì and Rimini, about $18 \mathrm{~km}$ from the Adriatic sea. Cesena is watered by the Savio river, which is about 125 km long (Figure 1).

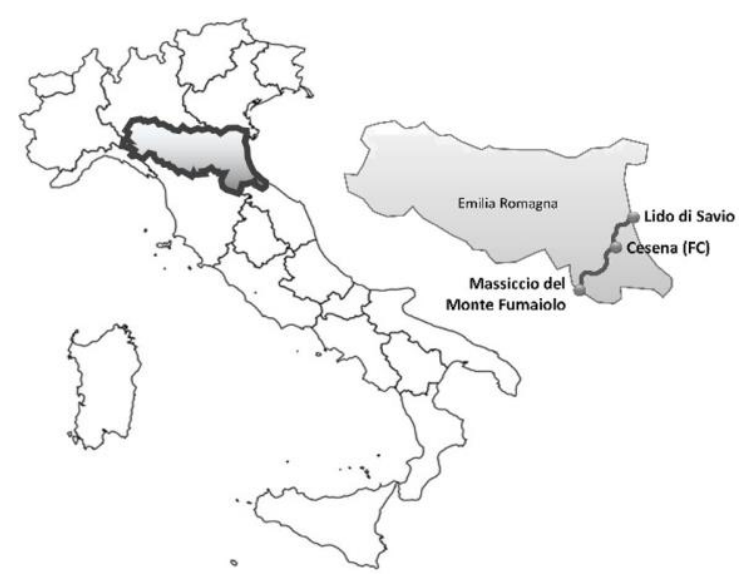

Figure 1. Localization of the Savio river in Emilia-Romagna (Italy)

During the Middle Ages, outside the city a sluice (chiusa di Cento) was realized for the Savio river, in order to carry water to the little channel (torrente Cesuola) for mill powering (Figure 2). The four mills of Cesena (Palazzo, Serravalle, Mezzo and Pino) were used over time for grinding of grain and cereals, fulling of clothes and, in later times, for tobacco processing and production of electricity. Today, the mills are no longer used, or they have even been demolished. Instead, the Cento sluice (Figure 2) and the Brenzaglia hydroelectric power plant are still in operation.

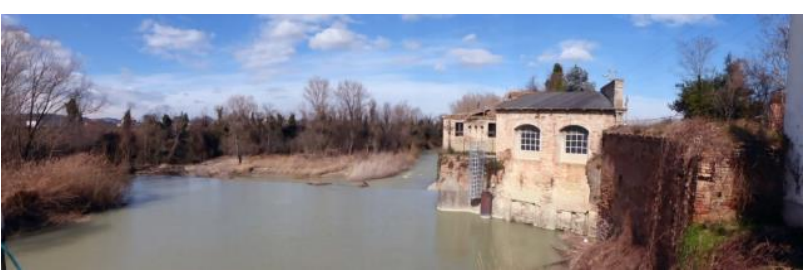

Figure 2. A current photo of the Cento sluice

\subsection{The mill company}

The most ancient document referring to the channel, the four mills and the sluice as an economic entity dates back to the end of the $14^{\text {th }}$ century. On the basis of the document, the Compagnia dei Molini di Cesena appears to have been the most ancient limited company in Italy (Armuzzi and Riva, 1976; Domeniconi, 1956; Sozzi, 1975; Zavatti, 1935). The company underwent various transfers of ownership over time (Figure 3), up to the acquisition by ENEL (the main Italian company for electricity distribution) in the second half of the $19^{\text {th }}$ century; it is for this reason that its statute was frequently updated (Figure $4)$.

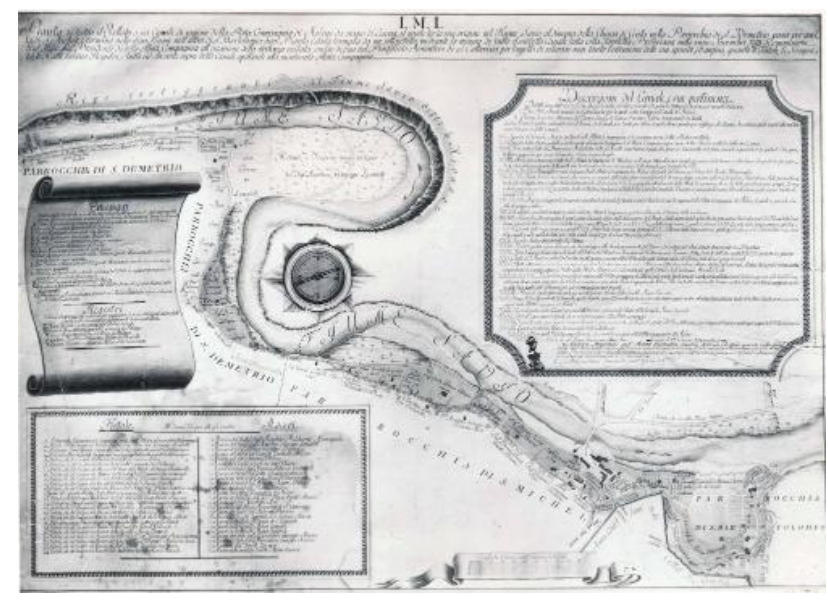

Figure 3. Papal bull for the sale of the mills to the company, 1476 (MiBACT, 2015)

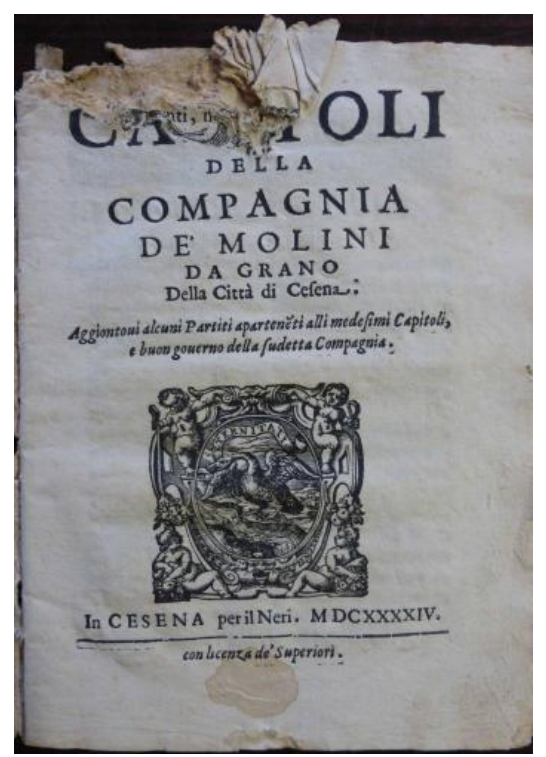

Figure 4. The first page of the mill company's statute, 1644 (MiBACT, 2015) 
Several events concerning the mills and the channel followed over time: changes of designed use of the mills, structural interventions on the mills (demolition and rebuilding, expansion and modernization), flood events of the Savio river, rupture and rebuilding of the Cento sluice, interventions for protection of the embankments, expansion and rebuilding of the Cesuola channel, construction of a tunnel in the Brenzaglia mountain, etc.

\subsection{Collection of historical maps and documents}

Thanks to a great variety of historical documents available for the studied area (maps, drawings and texts), it was possible to reconstruct the history of the channel for mill powering up today (Figure 5). An extensive search was made and several documents were found at different local institutions (Municipality of Cesena, State Archives of Forlì-Cesena, historical archives of the Romagna drainage consortium, Biblioteca Malatestiana library) (Figure 6). At the end, 8 historical maps (about 40 sheets in total) inherent the studied area (Table 7) and 80 archive documents (among which drawings, photos, specifications, regulations and administrative acts in general, newspaper articles), over a period of more than 600 years, were collected (Table 8). If not already in digital form, maps and documents were digitized with high resolution by means of large format scanners (Sgambati et al., 2006).

A great amount of historical documents exists concerning the area subject of the present study, because many events affecting the channel, the river, the mills, the mountain or the company occurred in history. Therefore, a tool for search and consultation of all archive materials results essential in studying the history of the area (Bartolini, 2015). In particular, the construction of a HGIS results a very good choice in this case, as explained in paragraph 3 .

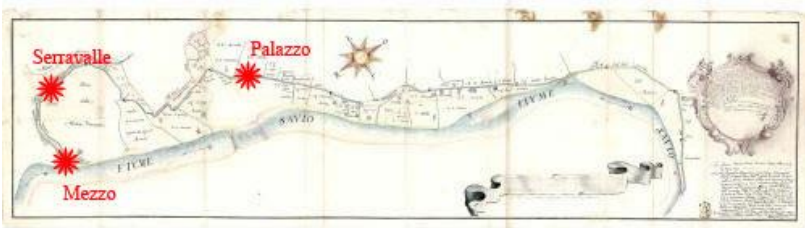

Figure 5. The Cesuola channel and a portion of Savio river in a map dating back to 1757 (MiBACT, 2015). The location of three mills represented here is highlighted in red

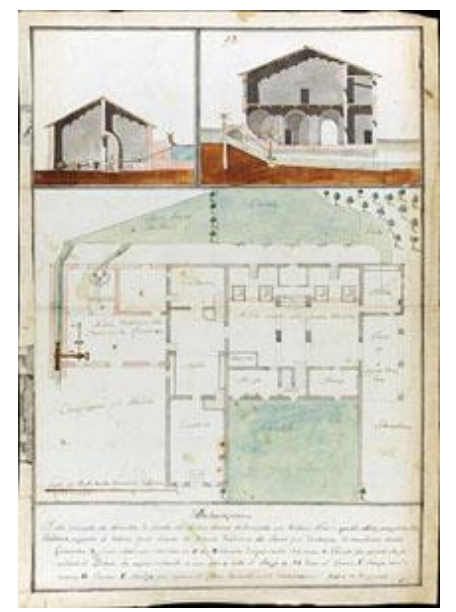

Figure 6. Plant of the Palazzo mill (which no longer exists), Guidi Mauro, 1792. The original document today is kept at the Biblioteca Malatestiana library of Cesena (Bartolini, 2015)

\begin{tabular}{|l|c|c|c|}
\hline Historical map & \multicolumn{3}{|c|}{ Features } \\
\hline & Year & Scale & Sheets \\
1. City of Cesena & 1740 & $\sim 1: 2000$ & 5 \\
2. Mill channel (Fig. 5) & 1757 & $\sim 1: 2000$ & 1 \\
3. Gregorian Cadastre & 1814 & $1: 2000$ & 9 \\
4. City of Cesena & 1820 & $1: 2000$ & 1 \\
5. Mill channel & 1826 & $\sim 1: 1000$ & 1 \\
6. Hydrography tables & 1846 & $\sim 1: 2000$ & 11 \\
7. Cadastre & 1926 & $1: 2000$ & 5 \\
8. Cadastre & 1953 & $1: 2000$ & 4 \\
\hline
\end{tabular}

Table 7. Historical maps inherent the studied area; year, scale and number of sheets composing the maps are reported

\begin{tabular}{|l|c|c|}
\hline Kind of documents & \multicolumn{2}{|c|}{ Features } \\
\hline & Period & N. of documents \\
drawings & $16^{\text {th }}-21^{\text {st }}$ century & 7 \\
photos & $20^{\text {th }}-21^{\text {st }}$ century & 32 \\
specifications & $18^{\text {th }}-21^{\text {st }}$ century & 11 \\
administrative acts & $14^{\text {th }}-21^{\text {st }}$ century & 21 \\
newspaper articles & $20^{\text {th }}-21^{\text {st }}$ century & 8 \\
\hline
\end{tabular}

Table 8. Historical documents inherent the studied area; kind, year, and number are reported

\section{CONSTRUCTION OF THE HGIS}

\subsection{Georeferencing and metric analysis}

All collected historical maps were firstly analysed in their metric fidelity by means of a specific software (MapAnalyst), in order to calculate the scale factor (the mean value and the range of variation), the North rotation and the entity of distortion with respect to current cartography. The result of analysis was displayed on each historical map by means of error vectors on GCPs, distortion grid and isolines illustrating local variation of scale factor (Jenny and Hurny, 2011) (Figure 9).

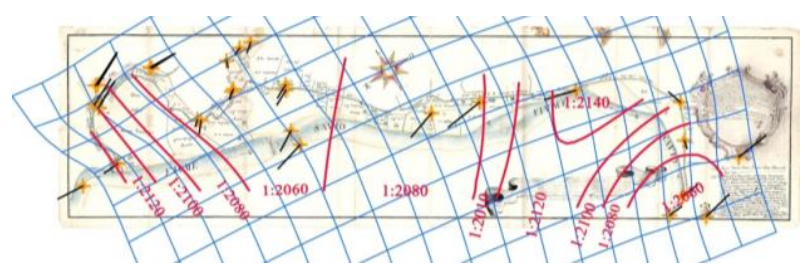

Figure 9. Graphic result of the deformation analysis on the map of Figure 5: GCPs with vector errors (black, exagg. factor 5),

Gauss-Boaga distortion grid (blue, mesh size 200 m, exagg. factor 5), scale isolines (magenta, interval $22.5 \mathrm{~m}$ )

Secondly, the maps were georeferenced in the Italian modern reference system (Gauss-Boaga, East fuse). To the aim, the current numerical cartography of the Municipality of Cesena (CTC), made in 2014 at 1:2000 nominal scale, was used as reference. For each sheet composing the maps, at least 6 Ground Control Points (GCPs) were recognized. The maps were georeferenced in reverse chronological order (i.e. from the most recent to the ancient one), so that each map, once georeferenced, could be used as reference for georeferencing of more ancient maps, if the recognition of points common to the modern cartography had been difficult due to the urban and environmental changes. Polynomial transformations were used, from the $1^{\text {st }}$ to the $3^{\text {rd }}$ order, according to number and distribution of the recognized GCPs, always aiming to a good compromise between adherence to the current map and containment of deformations. For georeferencing and 
subsequent processing purposes, the well-known QGIS open source software was used.

In Table 10, the results from georeferencing are reported for the maps described in Table 7. In case of maps made of more than one sheet, the mean number of GCPs and the mean RMSE for sheet are reported.

For the maps composed of more than one sheet, a digital mosaic needed. This was made in the GIS environment, on the base of only georeferencing information: the borders and overlapping parts between adjacent sheets were digitally removed, and a single georeferenced image for each map was resampled.

\begin{tabular}{|l|c|c|}
\hline Historical map & \multicolumn{2}{|c|}{ Georeferencing } \\
\hline 1. City of Cesena & Number of GCPs & RMSE [m] \\
2. Mill channel & 16 & 5.0 \\
3. Gregorian Cadastre & 33 & 4.3 \\
4. City of Cesena & 11 & 3.6 \\
5. Mill channel & 100 & 2.6 \\
6. Hydrography tables & 7 & 2.6 \\
7. Cadastre & 16 & 3.7 \\
8. Cadastre & 82 & 2.0 \\
\hline
\end{tabular}

Table 10. Number of GCPs and georeferencing errors (expressed as RMSE) for each analysed historical map

\subsection{Vectorization of the maps}

As the subject of study was the Savio river and the Cesuola channel with its mills, all these elements were vectorised on the historical maps, once georeferenced and eventually mosaicked (Figure 11). In order to build the HGIS, the historical maps and the modern ones (the current CTC and a modern orthophoto) were used as cartographic base. Therefore, the layers of the vectorised elements coupled with the map layers were organized in groups according to the age (one group for each period), disposed in chronological order. At the end, nine age groups were created (eight groups for the historical maps and one group for the modern cartography). This way, simply clicking on the groups in the legend, it is possible to turn on or off the maps overlaid with the related vectorised elements, and compare in an objective way the appearance that the landscape has taken over time, immediately recognizing eventual changes.

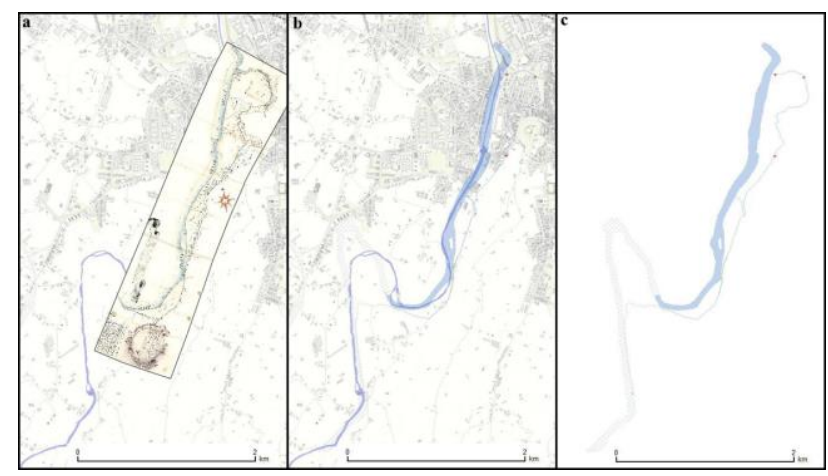

Figure 11. Results from georeferencing (a) and vectorization (b,

c) of the 1757 map; in (a) and (b) the current CTC is in background. The scale bar is $2 \mathrm{~km}$ long

\subsection{Hyperlinks}

In order to enrich the HGIS with data on the history of the channel and the mill company, the available archive documents, once digitized, were catalogued and organized in a database. Therefore, they were inserted into the GIS by means of hyperlinks: a vector layer of points was made for each historical map (i.e. for each age), composed by as many hotspots as documents related to that age exist. Each hotspot was located on the position/object that the related document refers to, and a link was created from the hotspot to the digital document preserved in the external database; about 110 hyperlinks were created in total. This way, inside the GIS, the documents can be retrieved and visualized simply clicking on the related hotspots, according to their age (Figure 12).

The vector layers of hotspots were included in the age groups with the maps and the vectorised elements. This way, selecting one age group, it is possible to turn on or off not only the map of that period and the related vectorised elements, but also the hyperlinks to the inherent archive documents (Figure 13) This tool proves to be a valid support for the study of the changes occurred in the area over time.

In order to facilitate the navigation, to each hotspot a symbol related to the kind of linked document was given (e.g. a book for administrative documents, a camera for the photos, etc.), together with a name reporting archive information (the current place where it is stored and the archive placement).

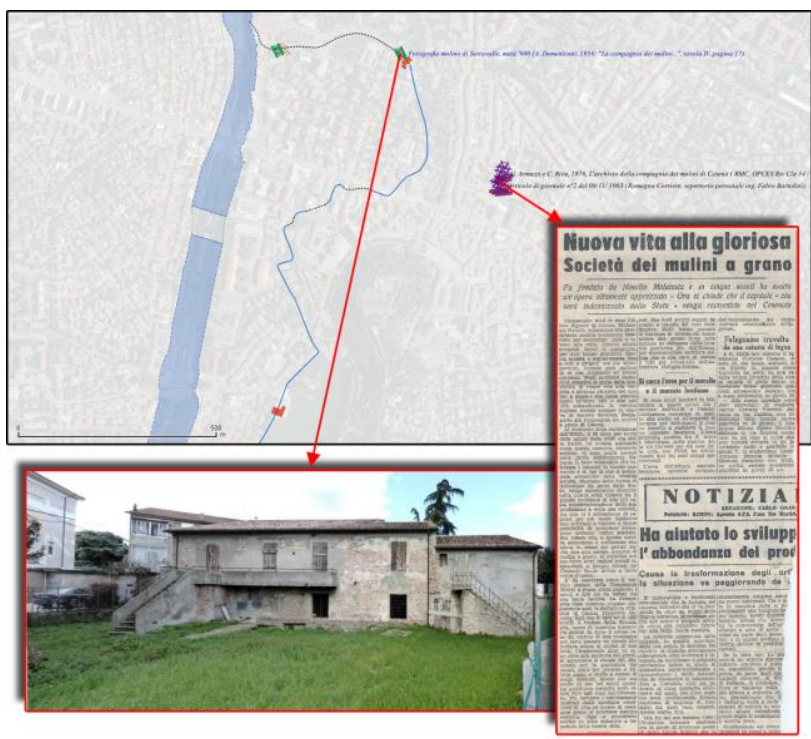

Figure 12. Two documents linked to the vector layer of 1953: a current photo of the Serravalle mill and a newspaper article about the mill company. The hotspots are identified by a specific symbol and a name reporting archive information

\section{RESULTS AND FUTURE DEVELOPMENTS}

\subsection{A new approach to archive searches}

The created HGIS proves to be a very useful tool for historians and archivists, because it can furnish a new approach to archive searches. In fact, in such a GIS environment, the subject (the Savio river, the Cesuola channel and its four mills) can be investigated according to modalities different from those usually adopted in archive, thanks to the following possibilities:

4.1.1 Navigation in space: By means of pan and zoom tools, it is possible to navigate in the studied area and localize points and objects on the maps; turning on or off the vector layers, it is possible to overlay the maps with the vector restitution of the river, the channel and the mills (Figure 13). 


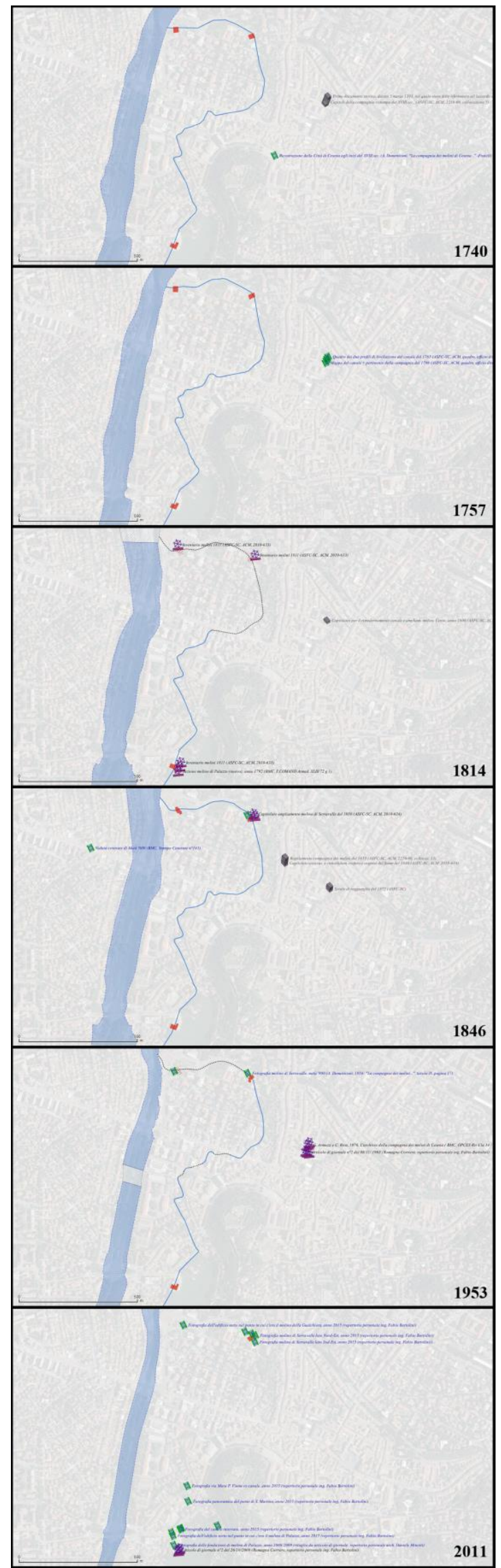

Figure 13. Vectorization of the river, the channel and the mills in some different historical periods. A modern orthophoto is displayed in background
4.1.2 Navigation in time: By means of an ad hoc timeline, or simply by clicking on the layers in legend, it is possible to turn on or off the layers relative to different ages, in order to compare the past with the present or two different periods in the past. This way, a trip across time, over a period of 600 years, can be simulated (Figure 14). By means of a specific tool, the documents preserved in the external database, and linked to the various hotspots of the displayed age, can always be retrieved and visualized. The age groups are arranged in chronological order in the legend, so that when two or more layers are turned on, maps and vectorizations overlay each other according to an age criterion.

4.1.3 Going beyond the walls of the owner institutions: The user can perform searches simply using a pc, without the need to consult the original documents at various institutions: maps and documents can be examined on the pc, this way avoiding the potential damage of the originals. However, if a direct consultation of the analogue documents results necessary, archive information (metadata) for the documents is always accessible in the GIS, allowing an immediate access to the originals.

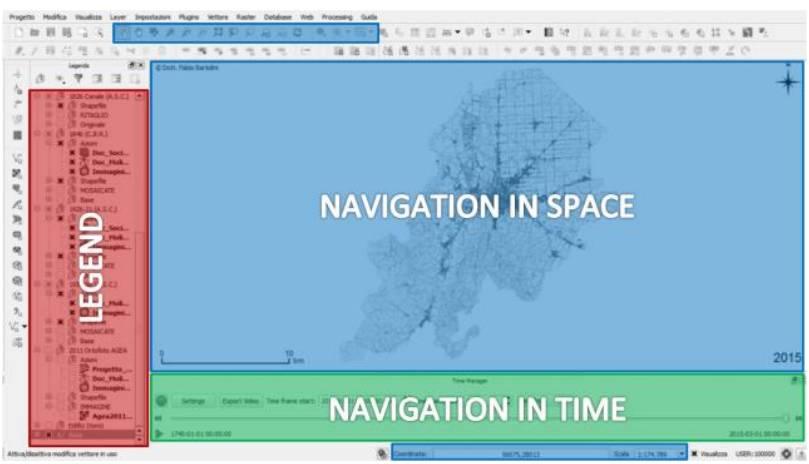

Figure 14. A screenshot of the HGIS; the legend and the areas for the navigation in space and time are highlighted in different colors

\subsection{Future developments}

The created HGIS results an open environment, as it can be enriched with more and more maps and documents. Moreover, having used an open platform like QGIS, it can be modified by any user. This research may foreshadow future installations of the HGIS at the institutions that own the documents, supporting archival activities, or be referred in museum events (see the project of redevelopment of the Serravalle mill in a local urban archaeology museum). A WebGIS application could be furthermore suitable and applicable starting from this prototype. Not by chance, the present research has recently attracted the attention of institutions and cultural associations interested in the rediscovery of historical documents, as well as the local community, during several cultural events organized on purpose (MiBACT, 2015).

\section{CONCLUSIONS}

The study aimed to prove the potentialities of GIS in supporting archive searches, by means of a singular case study, the ancient channel for mill powering near Cesena (Italy), that can be considered an example of industrial archaeology. The HGIS collects maps referred to eight historical periods and the present-day, and about 80 archive documents over a period of more than 600 years. In such a HGIS, the historical maps form 
the base for a spatial and temporal navigation, facilitated by a specific interface. The external documents linked to the maps complete the description of the represented elements, and allow reconstructing in space and time the evolution of the ancient channel and the history of this important mill company, in relation with the environmental context.

This HGIS is an example of how the GIS environment is able to offer new approaches to archive searches, as the subject can be investigated in its spatial and temporal dimensions at the same time, through simple and interactive navigation tools. For this reason, it proves to be useful to historians and archivists, also because it goes beyond the walls of the owner institutions. As a matter of fact, the research has recently attracted the attention of institutions and cultural associations interested in the rediscovery of historical documents related to an important phase of industrial development, as well as the local community. The central role of GIS has been recognized for preservation and investigation of Cartographic Heritage and other ancient documents, supporting specific studies together with the dissemination to a wide public.

\section{ACKNOWLEDGEMENTS}

We would like to acknowledge the institutions that furnished the materials to carry out the research: Municipality of Cesena, State Archives of Forlì-Cesena, historical archives of the Romagna drainage consortium, Biblioteca Malatestiana library of Cesena.

\section{REFERENCES}

Armuzzi, G., Riva, C., 1976. Studi Romagnoli, XXVII. L'archivio della Compagnia dei molini. Fratelli Lega Editori, Firenze.

Balletti, C., 2000. Analytical and quantitative methods for the analysis of the geometrical content of Historical Cartography. In: The International Archives of Photogrammetry and Remote Sensing, Amsterdam, Vol. XXXIII, Part B5, pp. 30-37.

Bartolini, F., 2015. Dalla carta antica al Sistema Informativo Territoriale: evoluzione storica dell'antico canale dei molini di Cesena. Stilgraf, Cesena.

Bianchi, F., 2013. Il Comune cerca la collaborazione dei privati per dare nuova vita agli edifici comunali inutilizzati. Municipality of Cesena, http://www.comune.cesena.fc.it/flex/cm/pages/ServeBLOB.php/ L/IT/IDPagina/12644 (15 April 2016).

Bitelli, G., Gatta, G., Girelli, V.A., Vittuari, L., Zanutta, A., 2011. Integrated Methodologies for the 3D Survey and the Structural Monitoring of Industrial Archaeology: The Case of the Casalecchio di Reno Sluice, Italy. International Journal of Geophysics, Vol. 2011. (2011), Article ID 874347, 8 pp., doi:10.1155/2011/874347.

Bitelli, G., Cremonini, S., Gatta, G., 2014. Cartographic Heritage: toward unconventional methods for quantitative analysis of pre-geodetic maps. Journal of Cultural Heritage, 15(2), pp. 183-195.

Brovelli, M.A., Kilsedar, C.E., Minghini, M., Oxoli, D., 2016. GIS-based analysis of a peculiar effect of urbanization: the case of the buried watercourses of Como (Italy). Applied Geomatics, pp. 1-15.

Casella, E., Symonds, J., 2005. Industrial Archaeology: Future Directions. Global Contributions to Historical Archaeology. 19, Springer Verlag.

Cossons, N., 2000. Perspectives on Industrial Archaeology, London Science Museum.

Domeniconi, A., 1956. La Compagnia dei molini di Cesena, origine, sviluppi e vicende dal sec. XIV ad oggi. Fratelli Lega Editori, Firenze.

Gatta, G., Bitelli, G., 2016. A historical GIS for the comparison of past and present views: Bologna, yesterday and today. Proceedings of the 11th Workshop "Digital Approaches to Cartographic Heritage”, Riga, Latvia, 20-22 April 2016.

Gregory, I., Healey, R., 2007. Historical GIS: structuring, mapping and analysing geographies of the past. Progress in Human Geography, 31(5), pp. 638-653.

Jenny, B., Hurny, L., 2011. Studying cartographic heritage: analysis and visualization of geometric distortions. Computers \& Graphics, 35-2, pp. 402-411.

Larson, R.R., 2003. Placing cultural events and documents in space and time. In: Duckham, M., Goodchild, M.F., Worboys, M.F. (eds.), Foundations of Geographic Information Science, Taylor \& Francis, London, pp. 223-239.

Livieratos, E., 2006. On the Study of the Geometric Properties of Historical Cartographic Representations. Cartographica, 412, pp. 165-175.

Lundberg, C., Peterson, L., 2005. Land use history of central Luleå: a case study in the use of historical maps together with modern geographic municipal information. Applied GIS, Vol. 1 No. 3, pp. 1-30.

MiBACT (Ministero dei Beni e delle Attività Culturali e del Turismo), 2015. Pane e macinato a Cesena nel XVIII secolo http://www.beniculturali.it/mibac/export/MiBAC/sito-

MiBAC/Contenuti/MibacUnif/Eventi/visualizza_asset.html_17 12940528.html ( $1^{\text {st }}$ April 2016).

Nobajas, A., 2014. Historical cartography as a tool to study of urban change. The case of Garriga i Roca's quarterons. Treballs de la Societat Catalana de Geografia, 77, pp. 205-220.

Schlichting, K., 2008. Historical GIS: New ways of doing history. Historical Methods, 41, pp. 191-196.

Sgambati, G., Benassati, G., Biancini, L., Buonora, P., Sinisi, D., Cantile, A., Delfino, L., Di Angelo Antonio, M., Falchetta, P., Mancinelli, M.L., Sanguineti, M.T., Serratrice, G., Truci, I., Valerio V., 2006. Linee guida per la digitalizzazione del materiale cartografico, Istituto Centrale per il Catalogo Unico delle biblioteche italiane e per le informazioni bibliografiche http://www.iccu.sbn.it/upload/documenti/linee_guida_digit_cart ografia_05_2006.pdf (24 March 2016).

Sozzi, S., 1975. I due molini di Palazzo della Compagnia dei molini a grano di Cesena. Camera di Commercio, Industria, Artigianato e Agricoltura di Forlì. 
Timár, G., Székely, B., Molnár, G., Ferencz, C., Kern, A., Galambos, C., Gercsák, G., Zentai, L., 2008. Combination of historical maps and satellite images of the Banat region - Reappearance of an old wetland area. Global and Planetary Change, Vol. 62, Issues 1-2, pp. 29-38.
Wilson, A., 2001. Sydney timemap: Integrating historical resources using GIS. Hist. Comput., 13 (1), 45-68.

Zavatti, A., 1935. Sul canale dei molini presso Cesena. Tipografia Arturo Bettini, Cesena. 